\title{
Palmaris Longus Tendon Absence in Pre-Clinical Medical Students of Universiti Malaysia Sabah
}

Navin Ravi ${ }^{1}$, Elvira Effie Juis ${ }^{1}$, Michelle Maria Vincent', Rasyidah Shokri' ${ }^{1}$, Vinooshana R. Kannan ${ }^{1}$, Izzudin Madin', Khairun Nadzihah¹, Khairul Azman'1, Aye Mya Thidar1*

${ }^{1}$ Faculty of Medicine and Health Sciences, Universiti Malaysia Sabah,

Kota Kinabalu, Sabah, Malaysia

\section{*Corresponding author's email: amtdteacher@gmail.com}

Received: 16 May 2018

Accepted: 18 October 2019

Keywords:

palmaris longus tendon, pre-clinical, medical students, Sabah

\section{ABSTRACT}

Palmaris longus $(P L)$ tendon is regularly used in reconstructive surgeries as a donor tendon because it is observed as an accessory muscle and has little practical use to the human hands. It is only found in mammals. For example, the orangutan has PL but it is absent variable in the higher class of apes such as gorillas and chimpanzees. The absence of PL in humans appears to be hereditary, but the genetic transmission is unclear. The main objective of this study is to determine the prevalence of $\mathrm{PL}$ tendon absence in pre-clinical medical students of UMS and to compare the lack between gender and ethnic groups. By using standard Schaffer's test, we examined the presence or absence of PL tendon among the first and second-year medical students of UMS. Four additional tests, Thompson's test, Mishra's test I, and II, Pushpakumar's tests were used to determine whether PL present or not. A total of 134 volunteers were examined, and $91.8 \%$ were right-handed, and $8.2 \%$ were left-handed. The overall absence (bilateral and unilateral) of PL tendon was $23.9 \%$, whereas unilateral absent was $17.9 \%$, and bilateral absent was $6.0 \%$. The high prevalence of absence of PL tendon among females $25.5 \%$ compared to males $\mathbf{2 0 . 0 \%}$. Chinese and Indian have a higher incidence of PL tendon absence followed by Kadazandusun and Malay. In this study, there were different figures for each ethnic group. The prevalence of absence of PL varies depending on the populations. 


\section{INTRODUCTION}

The prevalence of the absence of the Palmaris longus (PL) reported by Colombos in De Re Anatomica Libri in $\mathbf{1 5 5 9}^{1}$. It described that there is a wide variation of the prevalence of $\mathrm{PL}$ absence in different ethnic groups. Gender and ethnicity are the factors for the absence of PL. Eric et al. (2010) reported the comparison of PL absence concerning hand dominance ${ }^{2}$.

Among the flexor muscles of the forearm, $\mathrm{PL}$ is the most superficial flexor muscles. The muscle is slender and fusiform shaped. It is located between flexor carpi radialis and flexor carpi ulnaris muscles. It consists of a long tendon with short muscle belly. It originates from the medial epicondyle of the humerus. Weak flexion of the wrist and anchors the skin and fascia of the hand are the action of PL muscle ${ }^{3}$. Its principal function is to act as an anchor of the skin and fascia of the hand. It has been investigated that the PL tendon phylogenetically degenerates in flexion of the metacarpophalangeal joint. The median nerve lies partly under cover of the PL tendon at the wrist, and partially between the flexor carpi radialis and the PL tendon. Therefore, the median nerve is protected by the tendon. The median nerve becomes the most superficial structure in the wrist due to the absence of $\mathrm{PL}$. So during surgical incision and trauma, this nerve will be vulnerable to injury.

$\mathrm{PL}$ muscle is an accessory muscle with little function in the human upper limb. Therefore, often used in reconstructive surgeries ${ }^{1}$. For reconstruction surgery, PL tendon is the tendon of choice because of its long tendon and without producing any functional defect in the upper limb. By preoperative examination, the presence of $\mathrm{PL}$ tendon can be easily examined. At the time of birth, it is completely developed while fascia lata is not so well developed at that age. In reconstruction surgery by a hand surgeon, all these factors support it to become a commonly used donor tendon. For the repair of chin and lip defects, correction of ptosis as well as management of facial paralysis, plastic surgeons utilize the PL muscle ${ }^{3}$.

$\mathrm{PL}$ muscle is one of the most variable muscles in both number and form in the human body. This well-developed muscle is only found in mammals, mainly during weightbearing and ambulation where the forearm is used. For example, PL is always present in the orangutan but it is absent variable in the higher class of apes such as gorillas and chimpanzees. It has been found that the PL tendon is rapidly degenerating in humans ${ }^{2}$.

The objective of this research is to identify the prevalence of PL tendon absence in pre-clinical medical students of UMS and to compare the lack between gender and ethnic groups.

\section{MATERIALS AND METHODS}

This research included 134 students from first and second-year medical students of UMS which involved 40 males and 94 females from 18 to 20 years old. The respondents received a thorough and comprehensive briefing on the procedures of the study and had given informed written consent. They were also treated with professional courtesy and fairness as well as having their confidentiality protected as was agreed upon in the terms and agreement of the consent form. The subjects who had previous surgeries of the upper limb or who had any abnormalities of the upper limb were excluded. A general demographic questionnaire with hand dominance was followed by an examination of absence of the $\mathrm{PL}$ tendon. The investigators were using the standard Schaffer's test ${ }^{4}$ (thumb is opposed to the little finger while the wrist is flexed) to examine the presence or absence of PL tendon. The presence of $\mathrm{PL}$ tendon is determined by the protuberance under the skin at the wrist. It can be palpated and seen on inspection. Otherwise, the other four added tests, namely 
Thompson'stest ${ }^{5}$, Pushpakumar's test ${ }^{6}$, Mishra's 1 st and 2 nd tests ${ }^{7}$ were done to confirm the absence. If the PL tendon is still not visualised after performing the additional test, they are concluded to have an absence of PL tendon.

\section{Schaeffer's Test}

Subjects need to steady their forearm at $90^{\circ}$, then opposing the thumb to the little finger with the wrist partially flexed in Schaeffer's test (Figure1).

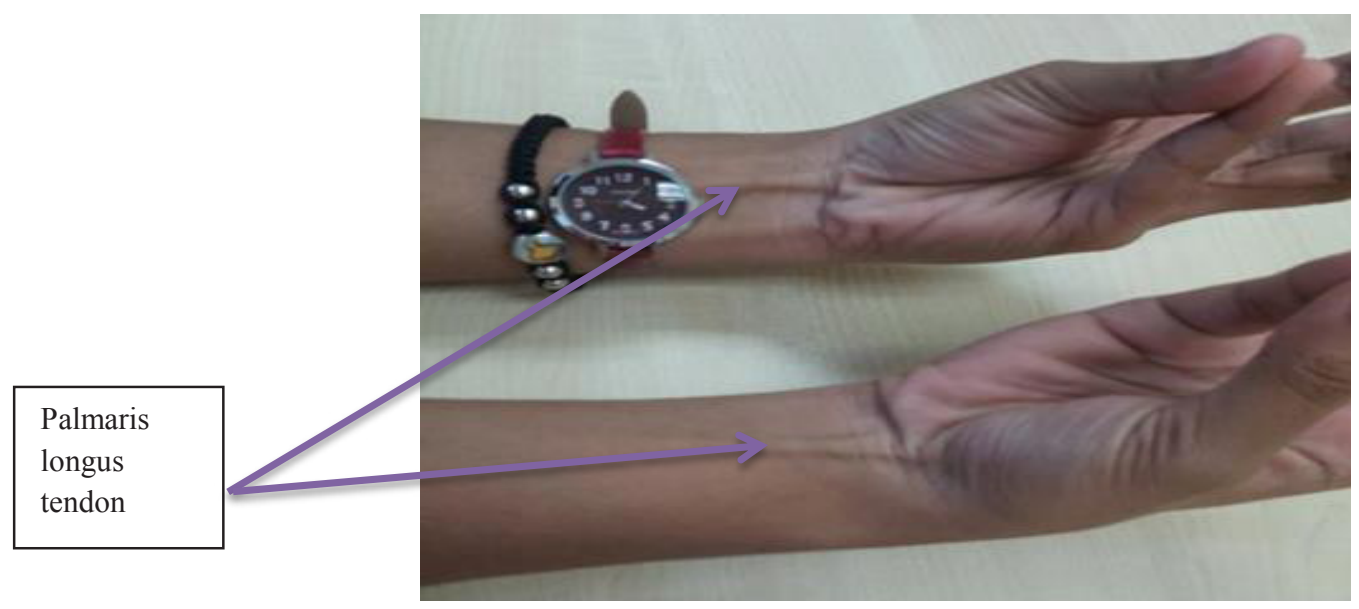

Figure 1 The arrows show the bilateral presence of PL (Schaeffer's test)

\section{Thompson's Test}

A fist needs to be made, followed by flexing the wrist against resistance with the thumb flexed over the fingers in Thompson's test (Figure 2).

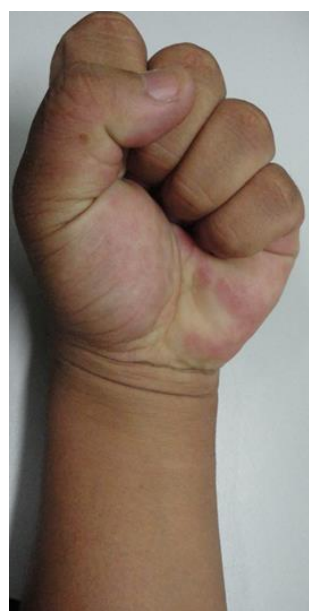

Figure 2 Unilateral absence of PL (Thompson's test)

\section{Pushpakumar's "Two-Finger Sign" Method}

The subjects need to fully extend the index and middle fingers, the wrist and other fingers were fully flexed with the thumb opposed and flexed in "two-finger sign" method of Pushpakumar's (Figure 3).

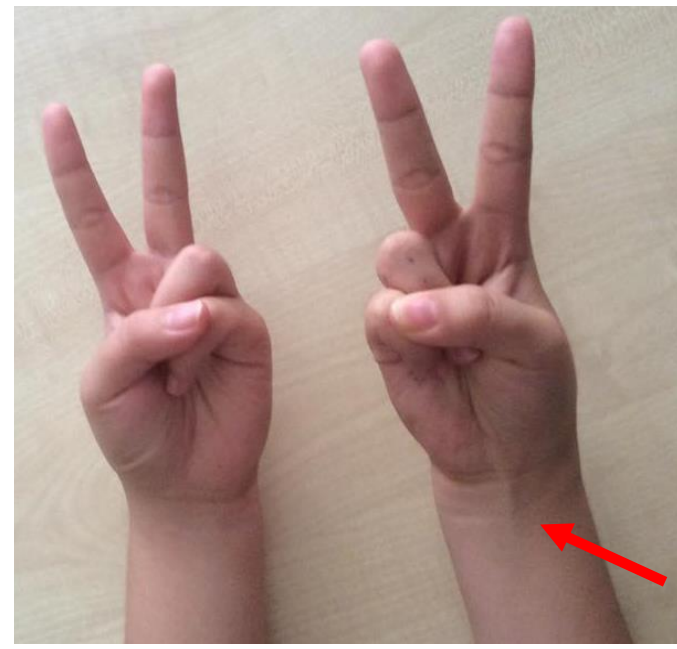

Figure 3 Unilateral absence of PL (Pushpakumar's test). The arrow shows the presence of PL only in the right hand

Mishra's 1st Test

Mild active flexion of the wrist with passive hyperextension of the metacarpophalangeal joints. 


\section{Mishra's 2nd Test}

Abduct the thumb against resistance with the wrist partially flexed.

SPSS version 22.0 software was used to analyse the data and to test the association between gender, ethnic and hand dominance with the absence of PL tendon by using a chisquare test.

\section{RESULTS}

\section{Overall Absence of PL Tendon}

Several 134 volunteers consisting of first and second-year medical students, 40 male students (29.9\%), and 94 female students (70.1\%) were examined in this study. In our research, there were 25 Malays (18.7\%),
42 Chinese (31.3\%), 34 Indians (25.4\%), 19 Kadazandusun (14.2\%), and 14 others (Bajau and Suluk) of $10.4 \%$. There were 123 righthanded students $(91.8 \%)$, whereas only 11 students were left-handed (8.2\%). The overall absence (bilateral and unilateral) of PL tendon was in 32 students (23.9\%).

\section{Gender and PL Tendon Absence}

The prevalence of the lack of PL (both bilateral and unilateral) among females (25.5\%) compared to males (20.0\%). Out of 134 subjects, 40 subjects were male $(29.9 \%)$, and 94 were female $(70.1 \%)$. The bilateral absence of $\mathrm{PL}$ is $7.4 \%$ in females but $2.5 \%$ in males. Unilateral absence on the left side was more common in females (12.8\%) than males (7.5\%). The one-sided absence of PL on the right side was higher among males (10.0\%) than females (5.3\%) (Tables 1 and 2).

Table 1 Absence of PL between gender

\begin{tabular}{|c|c|c|}
\hline Gender & PL tendon absent & PL tendon present \\
\hline Male & $\begin{array}{c}8 \\
(20.0 \%)\end{array}$ & $\begin{array}{c}32 \\
(80.0 \%)\end{array}$ \\
\hline Female & $\begin{array}{c}24 \\
(25.5 \%)\end{array}$ & $\begin{array}{c}70 \\
(74.5 \%)\end{array}$ \\
\hline
\end{tabular}

Pearson Chi-Square $=0.472, p>0.05$

Table 2 Bilateral and unilateral absence of PL between gender

\begin{tabular}{ccccc}
\hline Gender & $\begin{array}{c}\text { Unilateral right } \\
\text { absent }\end{array}$ & $\begin{array}{c}\text { Unilateral left } \\
\text { absent }\end{array}$ & Bilateral absent & Bilateral present \\
\hline Male & 4 & 3 & 1 & 32 \\
Female & $(10.0 \%)$ & $(7.5 \%)$ & $(2.5 \%)$ & $(80.0 \%)$ \\
\hline
\end{tabular}

Pearson Chi-Square $=\mathbf{2 . 8 7 3}, p>0.05$

\section{Ethnic Groups and PL Tendon Absence}

Only $7(16.7 \%)$, Chinese students had unilateral absent of PL tendon on the left side, whereas one in single absent on right side and bilateral absent in one subject.
There were four students (11.8\%) who had a one-sided absence of PL tendon on their right hand, three students (8.8\%) had bilateral absence (8.8\%) and two students (5.9\%) from the Indian ethnic group had unilateral absence on their left side. Among the Malays, the unilateral right absence is $2(8.0 \%)$ while 
unilateral remaining lack and bilateral absence take place at one student each (4.0\%). For the Kadazandusun ethnic group, 4 had unilateral absence on the left side (21.1\%), and $3(15.8 \%)$ had bilateral absence (Table 3 ).

Table 3 PL absence and ethnic groups

\begin{tabular}{|c|c|c|c|c|}
\hline Gender & Unilateral right absent & Unilateral left absent & Bilateral absent & Bilateral present \\
\hline Malay & $\begin{array}{c}2 \\
(8.0 \%)\end{array}$ & $\begin{array}{c}1 \\
(4.0 \%)\end{array}$ & $\begin{array}{c}1 \\
(4.0 \%)\end{array}$ & $\begin{array}{c}21 \\
(84.0 \%)\end{array}$ \\
\hline Chinese & $\begin{array}{c}1 \\
(2.4 \%)\end{array}$ & $\begin{array}{c}7 \\
(16.7 \%)\end{array}$ & $\begin{array}{c}1 \\
(2.4 \%)\end{array}$ & $\begin{array}{c}33 \\
(78.6 \%)\end{array}$ \\
\hline Indian & $\begin{array}{c}4 \\
(11.8 \%)\end{array}$ & $\begin{array}{c}2 \\
(5.9 \%)\end{array}$ & $\begin{array}{c}3 \\
(8.8 \%)\end{array}$ & $\begin{array}{c}25 \\
(73.5 \%)\end{array}$ \\
\hline Kadazan-Dusun & $\begin{array}{c}0 \\
(0.0 \%)\end{array}$ & $\begin{array}{c}4 \\
(21.1 \%)\end{array}$ & $\begin{array}{c}3 \\
(15.8 \%)\end{array}$ & $\begin{array}{c}12 \\
(63.2 \%)\end{array}$ \\
\hline Others & $\begin{array}{c}2 \\
(14.3 \%)\end{array}$ & $\begin{array}{c}1 \\
(7.1 \%)\end{array}$ & $\begin{array}{c}0 \\
(0.0 \%)\end{array}$ & $\begin{array}{c}11 \\
(78.6 \%)\end{array}$ \\
\hline
\end{tabular}

Pearson Chi-Square $=16.123, p>0.05$

\section{Hand Dominance and PL Absence}

Out of the 134 students, 123 were right-handed (91.8\%), and 11 were left-handed (8.2\%). Among the right-handed students, 14 of them had a unilateral left absence of tendon (11.4\%), nine students had unilateral right absence (7.3\%). Seven right-handed students (5.7\%) had the bilateral absence of PL tendon. As for the left-handed students, the bilateral lack and one-sided absence of tendon on the left side were found in 1 student (9.1\%). Thus, the prevalence of PL tendon absence was higher among right-handed students (24.4\%) compared to the left-handed students (18.2\%) (Table 4).

Table 4 PL absence and hand dominance

\begin{tabular}{|c|c|c|c|c|}
\hline & $\begin{array}{l}\text { Unilateral right } \\
\text { absent }\end{array}$ & $\begin{array}{l}\text { Unilateral } \\
\text { absent }\end{array}$ & Bilateral absent & Bilateral present \\
\hline Right-handed & $\begin{array}{c}9 \\
(7.3 \%)\end{array}$ & $\begin{array}{c}14 \\
(11.4 \%)\end{array}$ & $\begin{array}{c}7 \\
(5.7 \%)\end{array}$ & $\begin{array}{c}93 \\
(75.6 \%)\end{array}$ \\
\hline Left-handed & $\begin{array}{c}0 \\
(0 \%)\end{array}$ & $\begin{array}{c}1 \\
(9.1 \%)\end{array}$ & $\begin{array}{c}1 \\
(9.1 \%)\end{array}$ & $\begin{array}{c}9 \\
(81.8 \%)\end{array}$ \\
\hline
\end{tabular}

\section{DISCUSSION}

$\mathrm{PL}$ belongs to the anterior compartment of the forearm. Proximally the muscle is attached to the medial epicondyle of the humerus, and distally to the distal half of the flexor retinaculum and apex of the palmar aponeurosis. The tendon passes over the flexor retinaculum to break into four ligamentous fibrous slips for all the digits except the thumb and form the palmar aponeurosis ${ }^{3}$. Hence, there is a strong reason to believe that palmar aponeurosis exists as the degenerated tendon of PL. As the human hand can perform normal functions without this muscle, the muscle becomes less important results in disuse atrophy $^{8}$.

A recent study was done by Holzgrefe et al. (2019) where the comparison between the sensitivity, specificity, and accuracy of physical examination with high-resolution sonography for the detection of the PL tendon in 136 wrists. In contrast with sonography, the 
results showed the sensitivity and specificity of the physical examination were $94 \%$ and $86 \%$ respectively ${ }^{9}$.

$\mathrm{PL}$ muscle is frequently described as variable muscles in both numbers and form? The presence or absence of PL tendon should be sought out early because of its potential use for surgical procedures. For reconstructive and aesthetic surgeries such as recurrent injuries of the flexor tendons, ligament reconstructions, pulley reconstruction, reconstructions and ligaments of the thumb and elbow, ocular defects, blepharoptosis and other surgical reconstructions need the knowledge of the prevalence of $\mathrm{PL}$ absence among particular population that will assist the surgeons in their choice of donor tendon ${ }^{10}$.

This study found that both-sided absence was more common in females than males. Left-sided absence was less common in males than in females. These findings were supported by the survey among ethnic groups of Sabah, which shows PL absence is more common in females and on the left side ${ }^{11}$.

It is understandable that the prevalence of the absence of PL varies depending on the different ethnicities in populations. Some investigators described that the highest rate of the lack of the PL muscle was among the Egyptians $^{12}$. Surprisingly, Caucasians had a high prevalence of absence of the PL than the African Americans and Asians ${ }^{13}$. In Universiti Kebangsaan Malaysia study, Malays had a higher prevalence of PL absence, followed by the Indians and lowest rate had in Chinese ${ }^{14}$. Whereas, in this study, Chinese (31.5\%) and Indian (26.5\%) ethnic groups have a higher prevalence of PL tendon absent than Malay and Kadazandusun ethnic group.

This study also showed the prevalence of PL absence related to hand-dominance. From this study, right-handed people have a higher incidence of PL absence than lefthanded people. Unilateral absence is higher among right-handed people than left-handed people. Bilateral absence is higher among lefthanded people.

Some inventors executed studies to ascertain the clinical implications. They observed that the grip strength of the hand was unaffected but the pinch strength of the fourth and fifth digit decreased in the absence of the $\mathrm{PL}$ in both sexes ${ }^{15}$. The PL may be considered as a useful anatomical landmark for grafting in hand surgeries. Carpal tunnel syndrome or compartment syndrome can be produced by anomalous PL in the carpal tunnel ${ }^{16}$. According to the Anatomists, absence or anomalous PL is also important in day-to-day clinical practice ${ }^{17}$.

The absence of PL tendon by clinical examinations would not confirm the total agenesis of the muscle, as in some studies conducted on human cadavers is one of the limitations of this study. Although this study highlighted that the PL absence prevalence was much higher in the female population and more commonly absent on the left side. Most of the studies concluded that the absence of $\mathrm{PL}$ is more common in women and on the left side, although the differences were usually not significant when analysed statistically. This study found similar findings, but the differences were not significant. So, although this research between gender, ethnicity and hand dominance with PL absence is not substantial, it corresponded to previous studies.

\section{CONCLUSION}

This study finding concluded that the PL absence is more common in female, on the left side with a higher prevalence in the righthanded people. Palmaris longus tendon is unilaterally absent in $17.9 \%$ and both sides in $6.0 \%$ of its population, with an overall absence of $23.9 \%$. In relation to ethnic groups, Chinese (31.5\%) and Indian (26.5\%) had a higher prevalence of PL tendon absent than Malay 
and Kadazandusun ethnic group. Further study is required among the ethnic population of Sabah to determine the anatomical variations associated with PL absence.

\section{CONFLICT OF INTEREST}

The authors declare that they have no competing interests in publishing this article.

\section{REFERENCES}

1. Sebastin SJ, Lim AYT, Wong HB. (2006). Clinical assessment of absence of the palmaris longus and its association with other anatomical anomalies - A Chinese population study. Ann Acad Med Singapore 35: 249 - 253.

2. Erić M, Krivokuća D, Savović S, et al. (2010). Prevalence of the Palmaris longus through clinical evaluation. Surg Radiol Anat 32: 357 - 361.

3. Susan Standring. (2016). Pectoral girdle and upper limb. Gray's Anatomy. 41st Ed, Churchill Livingstone, Elsevier pub. pp. 837 - 851.

4. Schaeffer JP. (1909). On the variation of the Palmaris longus muscle. Anat Rec 3: 275 278.

5. Thompson NW, Mockford BJ, Cran GW. (2001). Absence of the Palmaris longus muscle: Population study. Ulser Medical Journal 70: 22 - 24.

6. Pushpakumar SB, Hanson RP, Carroll S. (2004). The 'two finger' sign. Clinical examination of Palmaris longus tendon. Br. J. Plast. Surg 57: $184-185$.

7. Mishra S. (2001). Alternative tests in demonstrating the presence of Palmaris longus. Indian J Plast Surg 34: 12.

8. Roqueline A, Aversi F, Rafael VB et al. (2014). Morphometric and statistical analysis of the palmaris longus muscle in human and non-human primates. BioMed Research International Volume 14: 17 - 23.
9. Holzgrefe RE, Anastasio AT, Farley $\mathrm{KX}$ et al. (2019). Detection of the palmaris longus tendon: Physical examination versus sonography. Journal of Hand Surgery (European Volume) 44 (8): 800 - 804.

10. Angelini LC, Angelini FB, Oliveira BC et al. (2012). Use of the tendon of the palmaris longus muscle in surgical procedures: Study on cadavers. Acta Ortop Bras 21 (4): 226 - 229.

11. Aye Mya Thidar, Tin Tin Myint, Daw Khin Saw Naing, Zainal Ariffin Mustapha. (2013). Palmaris longus agenesis among Dusun and Bajau ethnic groups of Northern Borneo. International Jour of Collaborative Research on Internal Medicine \& Public Health 5 (6): $386-397$.

12. Raouf HA, Kader GA, Jaradat A et al. (2013). Frequency of palmaris longus absence and its association with other anatomical variations in the Egyptian population. Clin Anat 26 (5): 572 - 577.

13. Soltani AM, Peric M, Francis CS. (2012). The variation in the absence of the palmaris longus in a multiethnic population of the United States: An epidemiological study. Plast Surg Int ID 282959.

14. Roohi SA, Choon Sian L, Shalimar A et al. (2007). A study on the absence of Palmaris longus in a multi-racial population. Malaysian Orthopaedic Journal 1 (1): 26 - 28.

15. Cetin A, Genc M, Sevil S, Coban YK. (2013). Prevalence of the palmaris longus muscle and its relationship with grip and pinch strength: a study in a Turkish pediatric population. Hand (NY) 8 (2): 215 - 220.

16. Julie Vercruyssen, Aldo Scafoglieri, Erik Cattrysse. (2016). The impact of palmaris longus muscle on function in sports: An explorative study in elite tennis players and recreational athletes. J. Funct. Morphol. Kinesiol 1: 167 - 182.

17. Das S, Farihah S. (2013). Palmaris longus muscle: Presence or absence, does it matter? Med \& Health 8 (1): $1-2$. 
